\title{
Loss of Dendritic HCN1 Subunits Enhances Cortical Excitability and Epileptogenesis
}

\author{
Zhuo Huang, ${ }^{1}$ Matthew C. Walker, ${ }^{2}$ and Mala M. Shah ${ }^{1}$ \\ ${ }^{1}$ Department of Pharmacology, The School of Pharmacy, University of London, London WC1N 1AX, United Kingdom, and ${ }^{2}$ UCL Institute of Neurology, \\ University College London, London WC1N 3BG, United Kingdom
}

Hyperpolarization-activated cation nonselective 1 (HCN1) plasticity in entorhinal cortical (EC) and hippocampal pyramidal cell dendrites is a salient feature of temporal lobe epilepsy. However, the significance remains undetermined. We demonstrate that adult HCN1 null mice are more susceptible to kainic acid-induced seizures. After termination of these with an anticonvulsant, the mice also developed spontaneous behavioral seizures at a significantly more rapid rate than their wild-type littermates. This greater seizure susceptibility was accompanied by increased spontaneous activity in $\mathrm{HCN1}^{-1-}$ EC layer III neurons. Dendritic $I_{\mathrm{h}}$ in these neurons was ablated, too. Consequentially, $\mathrm{HCN1}^{-1-}$ dendrites were more excitable, despite having significantly more hyperpolarized resting membrane potentials (RMPs). In addition, the integration of EPSPs was enhanced considerably such that, at normal RMP, a $50 \mathrm{~Hz}$ train of EPSPs produced action potentials in $\mathrm{HCN1}^{-/-}$neurons. As a result of this enhanced pyramidal cell excitability, spontaneous EPSC frequency onto $\mathrm{HCNI}^{-1-}$ neurons was considerably greater than that onto wild types, causing an imbalance between normal excitatory and inhibitory synaptic activity. These results suggest that dendritic HCN channels are likely to play a critical role in regulating cortical pyramidal cell excitability. Furthermore, these findings suggest that the reduction in dendritic HCN1 subunit expression during epileptogenesis is likely to facilitate the disorder.

\section{Introduction}

Temporal lobe epilepsy (TLE) is the most common, drugresistant form of the human condition (Engel, 1996; Herman, 2002). There is substantial evidence to suggest that the entorhinal cortex (EC) and hippocampus play pivotal roles in the induction and maintenance of TLE (Spencer and Spencer, 1994). EC layer III pyramidal neurons, particularly, may play a critical role (Du et al., 1993, 1995; Jones, 1993; Barbarosie et al., 2000; Avoli et al., 2002; Wu and Leung, 2003; Shah et al., 2004; Dawodu and Thom, 2005; Wozny et al., 2005). Indeed, they have been shown to be spontaneously hyperactive in vivo after the induction of TLE (Shah et al., 2004). Furthermore, their axons (the temporoammonic pathway), which innervate the stratum lacunosum-moleculare of CA1 and the molecular layer of the subiculum, have been suggested to provide the major excitatory drive to the hippocampus during chronic TLE (Barbarosie et al., 2000; Avoli et al., 2002; Wu and Leung, 2003; Wozny et al., 2005; Ang et al., 2006). Thus, altered EC layer III pyramidal cell excitability is likely to have a large impact on the development of TLE.

Received March 26, 2009; revised July 2, 2009; accepted July 18, 2009.

This work was supported by a Medical Research Council New Investigator Award and Epilepsy Research Foundation UK and Royal Society project grants (M.M.S.). We are grateful to S. Martin (University College London Sequencing and Genotyping Facility, London, UK) for genotyping the HCN transgenic mice. We also thank Prof. D. Johnston (University of Texas at Austin, Austin, TX), Prof. D. A. Brown (University College London, London, UK), and Dr. M. F. Nolan (Edinburgh University, Edinburgh, UK) for useful discussions and critically reading our manuscript.

This article is freely available online through the J Neurosci Open Choice option.

Correspondence should be addressed to Dr. Mala M. Shah, Department of Pharmacology, The School of Pharmacy, University of London, 29-39 Brunswick Square, London WC1N 1AX, UK. E-mail: mala.shah@pharmacy.ac.uk. DOI:10.1523/JNEUROSCI.1531-09.2009

Copyright $\odot 2009$ Society for Neuroscience ～0270-6474/09/2910979-10\$15.00/0
Interestingly, enhanced EC layer III neuronal excitability during TLE is accompanied by a decrease in the hyperpolarizationactivated cation current, $I_{\mathrm{h}}$ (Shah et al., 2004). Hyperpolarizationactivated cation nonselective (HCN) subunits underlie $I_{\mathrm{h}}$ (Robinson and Siegelbaum, 2003). The HCN1 subunit is predominantly expressed in the cortex and hippocampus, in which it is primarily located in pyramidal cell dendrites (Lörincz et al., 2002; Notomi and Shigemoto, 2004). Indeed, HCN1 expression is significantly reduced in the EC after TLE (Shah et al., 2004; Powell et al., 2008). Similar HCN1 channel plasticity has also been shown to occur in neocortical and hippocampal neurons in multiple animal models (Brewster et al., 2002; Bender et al., 2003; Dugladze et al., 2007; Jung et al., 2007; Shin et al., 2008; Marcelin et al., 2009) as well as humans (Brewster et al., 2002). This is surprising because the current depolarizes the resting membrane potential (RMP) (Pape, 1996; Robinson and Siegelbaum, 2003), and, hence, a decline in $I_{\mathrm{h}}$ might be expected to reduce excitability. However, $I_{\mathrm{h}}$ inhibition has been suggested to enhance pyramidal cell dendritic excitability by increasing the availability of $\mathrm{Ca}^{2+}$ channels (Tsay et al., 2007), as well as by amplifying the membrane resistance $\left(R_{\mathrm{N}}\right)$ (Magee, 1998; Stuart and Spruston, 1998), thereby modifying synaptic signal integration (Magee, 1999). Because $I_{\mathrm{h}}$ and HCN1 plasticity is a prevalent hallmark of TLE (Chen et al., 2001; Brewster et al., 2002; Bender et al., 2003; Shah et al., 2004; Dugladze et al., 2007; Jung et al., 2007; Dyhrfjeld-Johnsen et al., 2008; Powell et al., 2008; Shin et al., 2008; Marcelin et al., 2009), it is crucial to determine whether alterations in $I_{\mathrm{h}}$ and HCN1 protein expression during TLE are consequential to neural network adaptation or critically influence the disorder. In this study, we have used HCN1 null 
mice together with in vivo electroencephalographic recordings, in vitro electrophysiological analysis, and selective pharmacological tools to address this important question.

\section{Materials and Methods}

HCN1 null mice. HCN1 heterozygote breeding pairs were a kind gift from Prof. E. R. Kandel (Columbia University, New York, NY). Hybrid $\left(\mathrm{HCN1}^{+/-}\right)$male and female progeny were maintained on a 129SVEV background and crossed to obtain mixtures of HCN1 null mice, heterozygotes, and wild-type (WT) littermates as described previously (Nolan et al., 2003, 2004). These mice had been backcrossed for 10 generations. The mouse genotype was determined using PCR. Briefly, genomic DNA was extracted from $0.2 \mathrm{~cm}$ tail snips using the HOtShot protocol as detailed by Truett et al. (2000). A PCR reaction was then performed using TAQ polymerase (Bioline) and the following primers: oMR3410, 5' -CAC CTG CTA CGC AAT GTT TG-3'; oMR3411, 5'-ATT GGG CAC TAC ACG CTA GG-3'; oMR3412, 5'-AGA GAA ATC ATT CCC CGT GA-3'.

The PCR reaction consisted of an initial $2 \mathrm{~min}$ at $94^{\circ} \mathrm{C}$, followed by 35 cycles of $30 \mathrm{~s}$ at $94^{\circ} \mathrm{C}, 30 \mathrm{~s}$ at $55^{\circ} \mathrm{C}$, and $45 \mathrm{~s}$ at $72^{\circ} \mathrm{C}$. After the last cycle, the reaction is kept at $72^{\circ} \mathrm{C}$ for $4 \mathrm{~min}$ and then held at $10^{\circ} \mathrm{C}$. A $359 \mathrm{bp}$ band was observed for mice containing the wild-type allele, whereas a $450 \mathrm{bp}$ band was seen for mice containing the mutant allele. Heterozygotes contained both alleles.

Surgical procedure and electroencephalography. Six- to 8-week-old HCN1 null mice and wild-type littermate controls were anesthetized using a ketamine/xylamine mixture (Sigma) and positioned in a stereotaxic frame. Depth electrodes (Plastics One) were surgically implanted into the EC area using the following stereotaxic coordinates: $4.2 \mathrm{~mm}$ lateral to lambda and 4.0 $\mathrm{mm}$ below the cortical surface, with the nose bar set at $3.0 \mathrm{~mm}$ and the electrode holder at an angle of $17^{\circ}$ posterior to the sagittal plane.

All mice were kept on $12 \mathrm{~h}$ light dark cycles. Electroencephalographic (EEG) recordings were obtained $7 \mathrm{~d}$ later using a neurolog amplifier. Video recordings were obtained using a wired day/night camera with audio and infrared (Nature Cameras Ltd.). These together with the EEG data were simultaneously acquired on a computer using the micro1401 analog-todigital converter and spike 2 software (Cambridge Electronic Design). For baseline EEG, we did $6 \mathrm{~h}$ recordings during light cycle and $6 \mathrm{~h}$ during dark cycle for a minimum period of $5 \mathrm{~d}$. After kainate injections, $4 \mathrm{~h}$ EEG recordings were made during the light and dark cycles. All recordings were referenced to a frontal surface electrode. Recordings were visually inspected for electrographic seizure activity and interictal spikes as defined previously (Shah et al., 2004). Interictal spikes were defined as highamplitude (at least three times baseline amplitude) sharp transients lasting $<70 \mathrm{~ms}$. Electrographic seizure activity was defined as the appearance of high-amplitude (more than three times baseline activity), high-frequency, rhythmic activity with an evolution in spike fre-

\section{A Enhanced susceptibility of HCN1-/- mice to $\mathrm{KA}$ induced seizures}

(i) Control wildtype EEG

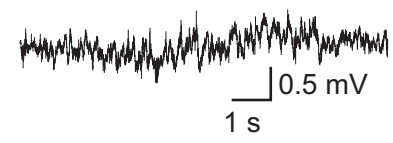

(iii) $\mathrm{Wt}+10 \mathrm{mg} / \mathrm{kg} \mathrm{KA}$

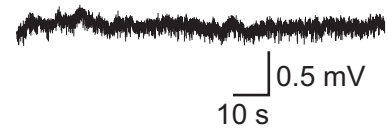

(v) $\mathrm{Wt}+20 \mathrm{mg} / \mathrm{kg} \mathrm{KA}$

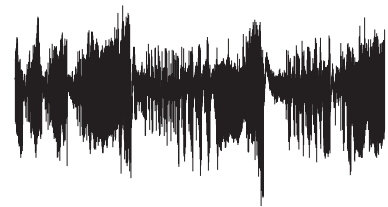

(ii) Control HCN1-/- EEG

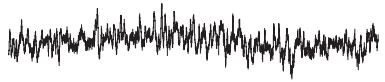

(iv) $\mathrm{HCN} 1-/-+10 \mathrm{mg} / \mathrm{kg} \mathrm{KA}$

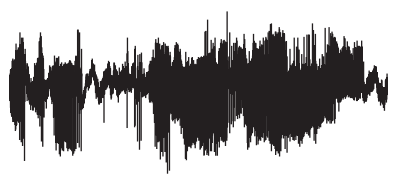

(vi)

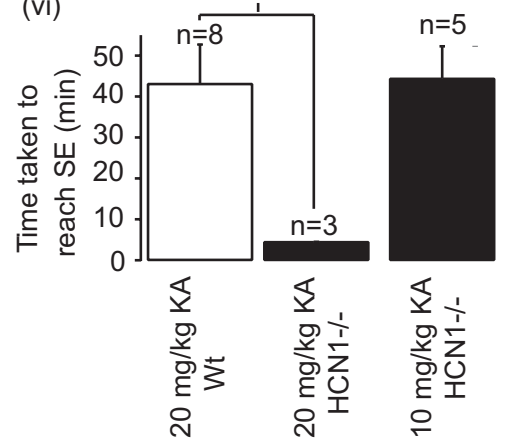

\section{B Significantly shorter latent period duration in HCN1-/- mice}

(i) EEG from HCN1-/- mouse 2 days following SE termination

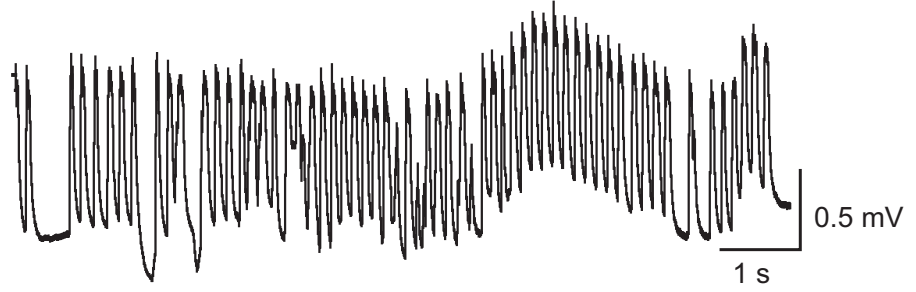

(ii) EEG from wildtype mouse 2 days following SE termination

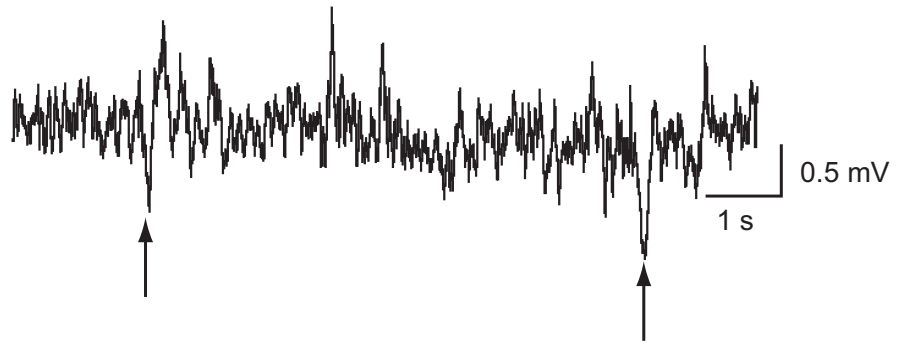

Figure 1. Enhanced seizure susceptibility and shorter latent period duration in $\mathrm{HCN1}^{-1-}$ mice. Ai, Aii, Example 10-s-long EEG recordings from untreated 8-week-old wild-type (WT or $\mathrm{HCN1}^{+/+}$) and $\mathrm{HCN1}^{-/-}$mice. Calibration in Ai applies to Aii. Aiii- $\mathbf{A v}$, One hundred second sections of EEG obtained $\sim 1 \mathrm{~h}$ after treatment with KA. Calibration in Aiiii is applicable to Aiv and Av, too. Avi, $G$ raph to depict the time taken to reach SE after administration of KA. The numbers of observations are indicated above each bar. ${ }^{*} p<0.05$. Bi, Example EEG recording of seizure activity obtained from an $\mathrm{HCN1}^{-1-}$ mice $\sim 2 \mathrm{~d}$ after termination of KA-induced SE. Bii, EEG traces to show that only interictal spikes (indicated by arrows) were present in a WT mouse $\sim 2 \mathrm{~d}$ after cessation of KA-induced SE. 
to induce class V seizures [as defined by the Racine scale (Racine, 1972)]. These were terminated $1 \mathrm{~h}$ after onset using sodium pentobarbital (30 $\mathrm{mg} / \mathrm{kg}$, s.c.; Sigma-Aldrich). Control groups were mice that had been treated SP only $(30 \mathrm{mg} / \mathrm{kg}$, s.c.). In some mice, EEG recordings were obtained after kainic acid administration. These were quantified as described by Lehmkuhle et al. (2009). Briefly, EEG raw data was initially bandpass filtered in the gamma band range $(20-70 \mathrm{~Hz})$ and the ratio of the gamma band power (the square of the average amplitude root mean square value) before and after kainic acid-induced seizures was calculated and expressed as a percentage. As described by Williams et al. (2009), the latent period duration was calculated as the time taken for the onset of motor seizures [typically class III, as defined by Racine (1972)]. All procedures concerning animals were approved by the United Kingdom Home Office.

Electrophysiological studies. Entorhinal-hippocampal slices were obtained from 6- to 9-week-old $\mathrm{HCN1}^{-/-}$and $\mathrm{HCN1}^{+/+}$(wild type) mice as described previously (Shah et al., 2004). Whole-cell and cell-attached recordings were obtained from both the soma and dendrites of EC layer III pyramidal neurons. For recording purposes, slices were placed in a chamber containing external recording solution maintained at $34-36^{\circ} \mathrm{C}$ and viewed using an Olympus BX51W1 equipped with differential infrared optics. The external solution (unless otherwise noted) was supplemented with $0.05 \mathrm{~mm}$ APV, $0.01 \mathrm{~mm}$ CNQX, $0.01 \mathrm{~mm}$ bicuculline, and 0.001 mм CGP 55845 [(2S)-3-[(1S)-1-(3,4-dichlorophenyl)ethyl]amino-2hydroxypropyl)(phenylmethyl)phosphinic acid]. The internal recording pipette solution for whole-cell current-clamp and EPSC voltage-clamp recordings was composed of the following (in $\mathrm{mM}$ ): $120 \mathrm{KMeSO}_{4}, 20 \mathrm{KCl}$, 10 HEPES, $2 \mathrm{MgCl}_{2}$, 0.2 EGTA, $4 \mathrm{Na}_{2}$-ATP, 0.3 Tris-GTP, and 14 Trisphosphocreatine, $\mathrm{pH}$ was adjusted to 7.3 with $\mathrm{KOH}$. To record spontaneous IPSCs, $\mathrm{KMeSO}_{4}$ was replaced with $\mathrm{KCl}$. Furthermore, ZD7288 (4-ethylphenylamino-1,2-dimethyl-6-methylaminopyrimidinium chloride) $(15 \mu \mathrm{M})$ was added to the intracellular solution when EPSC and IPSC recordings were made. In addition, for cell-attached recordings, the internal pipette solution contained the following (mM): $120 \mathrm{KCl}, 20$ tetraethylammonium-Cl, 5 4-AP, $1 \mathrm{BaCl}_{2}, 10$ HEPES, $1 \mathrm{MgCl}_{2}, 2 \mathrm{CaCl}_{2}$, 0.001 tetrodotoxin, and $0.1 \mathrm{NiCl}_{2}, \mathrm{pH}$ adjusted to 7.3. Pipettes containing any of these internal solutions had resistances of 5-12 $\mathrm{M} \Omega$. Whole-cell current-clamp recordings were obtained using a bridgemode amplifier (AxoClamp 2B; Molecular Devices), filtered at $10 \mathrm{kHz}$, and sampled at $50 \mathrm{kHz}$. Series resistance was usually in the order of $10-30$ $\mathrm{M} \Omega$ and was $\sim 70 \%$ compensated for the whole-cell voltage-clamp recordings. Cell-attached recordings were obtained using the Axopatch 200B (Molecular Devices), filtered $2 \mathrm{kHz}$, and sampled at $3.5 \mathrm{kHz}$. Data were acquired using pClamp 8.2 (Molecular Devices).

$\alpha$ EPSPs were generated by current injection of the order: $A=(t / \tau)$ * $\exp (1-(t / \tau)$, where $A$ is the amplitude of the current injected, and $\tau$ is the rise time constant. Tungsten electrodes (A-M Systems) were placed in EC layer I to elicit EPSPs. All drugs were bath applied. The effects of ZD7288 (15 $\mu \mathrm{M})$ occurred within $15 \mathrm{~min}$, and recordings were usually made within 25 min of application.

Data analysis. pClamp software was used to analyze whole-cell current-clamp and cell-attached voltage-clamp recordings. The $R_{\mathrm{N}}$ was calculated from $400 \mathrm{~ms}$ hyperpolarizing pulses of $100 \mathrm{pA}$ applied from a holding potential of $-70 \mathrm{mV}$. The $\alpha$ EPSP decay time constants were obtained by fitting the double-exponential function: $A_{1} e^{(-t / \tau 1)}+$ $A_{2} e^{(-t / \tau 2)}$, where $\tau 1$ and $\tau 2$ represent time constants of the initial and falling phase of the $\alpha$ EPSPs. Because $I_{\mathrm{h}}$ is activated during the falling phase of the $\alpha$ EPSP, only $\tau 2$ was used. The summation ratio of EPSPs was calculated as the ratio of the peak of the fifth EPSP to that of the first EPSP. Action potential threshold was determined as the point before the first derivative of the trace was no longer equal to zero. For cellattached recordings, the steady-state current after the $2 \mathrm{~s}$, hyperpolarizing step was used as an indication of the amount of $I_{\mathrm{h}}$. EPSCs and IPSCs were analyzed using the Mini-analysis program (version 6.07; Synaptosoft). Events $>3 \mathrm{pA}$ in amplitude were detected and used for analysis. Decay times and amplitudes of these events were obtained by fitting the averaged EPSC or IPSC with a single-exponential equation: $I(t)=A \exp (-t / \tau)$, where $I$ is the current amplitude at any given time

\section{A Dendritic Cell-attached Voltage Clamp Recordings}

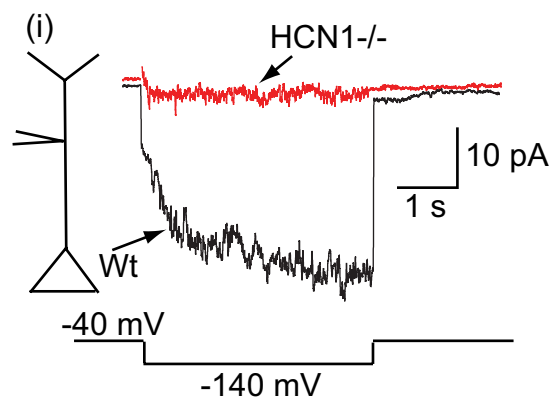

B Dendritic Whole-cell Current Clamp Recordings

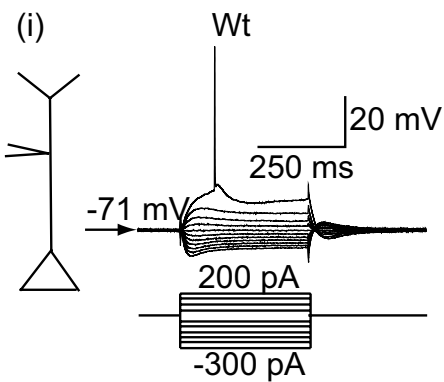

(ii) HCN1-/-

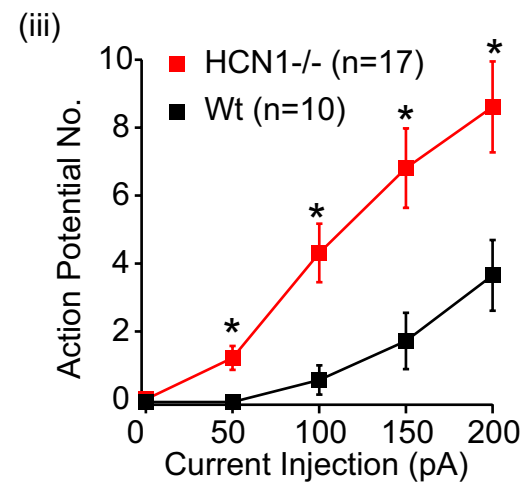

Figure 2. HCN1 deletion is accompanied by dendritic $I_{\mathrm{h}}$ ablation as well as increased dendritic excitability and dendritic $R_{N}$ in EC layer III pyramidal neurons. Ai, Recordings of $I_{h}$ obtained in the cell-attached mode from the apical dendrites of $\mathrm{HCN1}^{-1-}$ (red) and WT (black) EC layer III pyramids. The traces were obtained by applying a voltage step from -40 to $-140 \mathrm{mV}$ and then leak subtracted (leak current was obtained by applying a step from -40 to $-30 \mathrm{mV}$ ). The traces have also been superimposed to illustrate the difference in current amplitude. Bi, Bii, Example recordings obtained from $\sim 150 \mu \mathrm{m}$ along the apical dendrite of a WT and $\mathrm{HCN}^{-/-}$ neuron after application of a series of $400 \mathrm{~ms}$ steps from -300 to $+200 \mathrm{pA}$. The cells were held at the normal resting membrane potential. Calibration in Bi also applies Bii. Biii, Graph to show the average action potential numbers in response to varying current injections in WT and $\mathrm{HCN1}^{-1-}$ dendrites. In all cases, the $n$ values indicate the numbers of observations. ${ }^{*} p<0.05$.

$(t), A$ is the peak amplitude of the EPSC or IPSC, and $\tau$ is the decay time constant. Group data are expressed as mean \pm SEM. Statistical significance was determined using either paired or unpaired Student's $t$ tests as appropriate. Statistical significance of $p<0.05$ is indicated as * in all figures.

Materials. All chemicals were obtained from Sigma-Aldrich apart from ZD 7288, CGP 55848, CNQX, TTX, bicuculline, and APV, which were purchased from Ascent Scientific Ltd. Stock solutions of bicuculline and CGP 55848 were made in DMSO and stored at $-20^{\circ} \mathrm{C}$ until use. These were then dissolved in the external solution such that the final DMSO concentration was $<0.1 \%$. Aqueous stock solutions of ZD7288, CNQX, TTX, and APV were also kept at $-20^{\circ} \mathrm{C}$ until use. 


\section{Results}

HCN1 null mice have a lower seizure threshold and shorter latent period duration

To determine how HCN1 subunits influence epileptogenesis, $\mathrm{HCN} 1$ null mice were used. These mice have proved to be useful in exploring the role of $\mathrm{HCN} 1$ channels, because expression of HCN2HCN4 is minimally affected (Nolan et al., 2003, 2004, 2007; Tsay et al., 2007). To test the role of $\mathrm{HCN} 1$ subunits in influencing seizure susceptibility, depth electrodes were stereotaxically implanted in the EC of adult (7- to 9-week-old) HCN1 null mice and their wild-type littermates (see Materials and Methods). EEG recordings were obtained 7-10 d later from awake, freely moving mice present in their normal environment. As observed in the hippocampus (Nolan et al., 2004), no epileptiform abnormalities, interictal spikes, or spontaneous seizures were detected in the EEG recorded daily from $\mathrm{HCN1}^{-/-}$ $(n=7)$ or wild type $(n=8)$ for $6 \mathrm{~h}$ light and $6 \mathrm{~h}$ dark cycles over a period of 1-3 weeks (Fig. 1Ai,Aii) (total period of recording from seven $\mathrm{HCN1}^{-/-}$was $900 \mathrm{~h}$; total recording time from eight WT mice was $840 \mathrm{~h}$ ), indicating that these mice are not innately epileptic.

To investigate whether there were differences in seizure threshold and manifestation of TLE between $\mathrm{HCN1}^{-/-}$and wild-type mice, we used the commonly used so-called "kainate" model (Ben-Ari and Cossart, 2000; Dudek et al., 2002; White, 2002). In this model, a single episode of class $\mathrm{V}$ seizures [as defined by the Racine scale (Racine, 1972)] or status epilepticus (SE) is induced in rodents by administering kainic acid and then terminated $\sim 1 \mathrm{~h}$ later with an anticonvulsant such as sodium pentobarbital (see Materials and Methods). After a delay of a few weeks, known as the latent period (during which animals appear to be normal), spontaneous overt behavioral seizures occur (defined as the onset of chronic TLE) (Ben-Ari and Cossart, 2000; Dudek et al., 2002; White, 2002). This model is widely used because many of the clinical and pathological features of the human disorder (including the latent period) can be reproduced (Ben-Ari and Cossart, 2000; Dudek et al., 2002; White, 2002). As demonstrated previously (He et al., 2004), administration of $20 \mathrm{mg} / \mathrm{kg} \mathrm{KA}$ intraperitoneally elicited SE in wild-type mice in $43.1 \pm 9.6 \mathrm{~min}(n=8)$ (Fig. $1 A v)$. All wild types treated with $20 \mathrm{mg} / \mathrm{kg} \mathrm{KA}$ survived the treatment. This concentration, however, caused SE within $5 \mathrm{~min}$ in $\mathrm{HCN1}^{-/-}$ mice and was lethal $(n=3)$ (Fig. $1 A v i)$. Instead, half the amount of $\mathrm{KA}, 10 \mathrm{mg} / \mathrm{kg}$ delivered intraperitoneally, was required to induce SE in a similar time frame (Fig. 1 Aiv, Avi) and was not fatal. This lower dose had no effect in wild-type mice for up to $4 \mathrm{~h}$ ( $n=$ 4) (Fig. 1Aiii). EEG recordings showed that, despite the differences in dose, the intensity of KA-induced SE in $\mathrm{HCN1}^{-/-}$mice and wild types was comparable [percentage change in gamma band power during SE from baseline of $\mathrm{HCN1}^{-/-}$and wild type,
$143.75 \pm 18.75 \%(n=4)$ and $168.75 \pm 23.66 \%(n=4)$, respectively]. Because this was the case and the time taken to reach SE no different, we terminated the kainic acid-induced SE in both $\mathrm{HCN}^{-/-}$and wild types with sodium pentobarbital $(30 \mathrm{mg} / \mathrm{kg}$ s.c.) and used EEG recordings together with video monitoring to determine whether there were differences in the latent period duration (see Materials and Methods) as well. $\mathrm{HCN1}^{-/-}$mice displayed overt motor convulsions [class III forelimb clonus seizures as defined by Racine (1972)] within $72 \mathrm{~h}$ of halting SE (latent period duration, $60.0 \pm 7.3 \mathrm{~h} ; n=4$ ) (Fig. $1 B$ ). Conversely, wild types displayed similar spontaneous seizures $\sim 2$ weeks later (wild-type latent period duration, $386.8 \pm 11.1 \mathrm{~h} ; n=$ 4) (Fig. $1 B$ ). Hence, these mice appeared normal at $72 \mathrm{~h}$, and only interictal spikes were detected in EEG recordings (Fig. $1 \mathrm{Bii}$ ). These results, therefore, indicate that the decrease in HCN1 subunit expression that occurs in animal models and humans after TLE initiation (Brewster et al., 2002; Bender et al., 2003; Shah et al., 2004; Dugladze et al., 2007; Jung et al., 2007; Powell et al., 2008; Shin et al., 2008; Marcelin et al., 2009) is likely to have a substantial impact on the induction (seizure threshold) and expression of the disorder.

\section{Loss of $\mathrm{I}_{\mathrm{h}}$ in $\mathrm{HCN1}^{-/-}$EC layer III pyramid dendrites}

Because the EC (Jones, 1993; Spencer and Spencer, 1994; Avoli et al., 2002; Wu and Leung, 2003; Wozny et al., 2005) and EC layer 
A Somatic recordings at NRMP
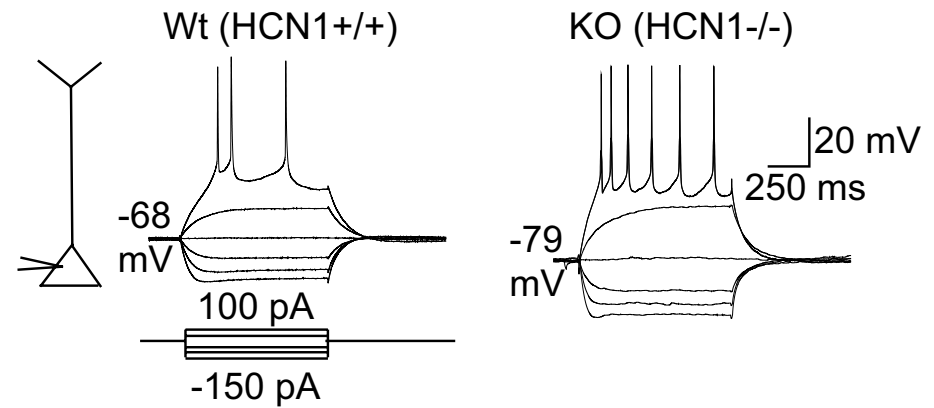

B Somatic recordings at $\mathbf{- 7 0} \mathrm{mV}$
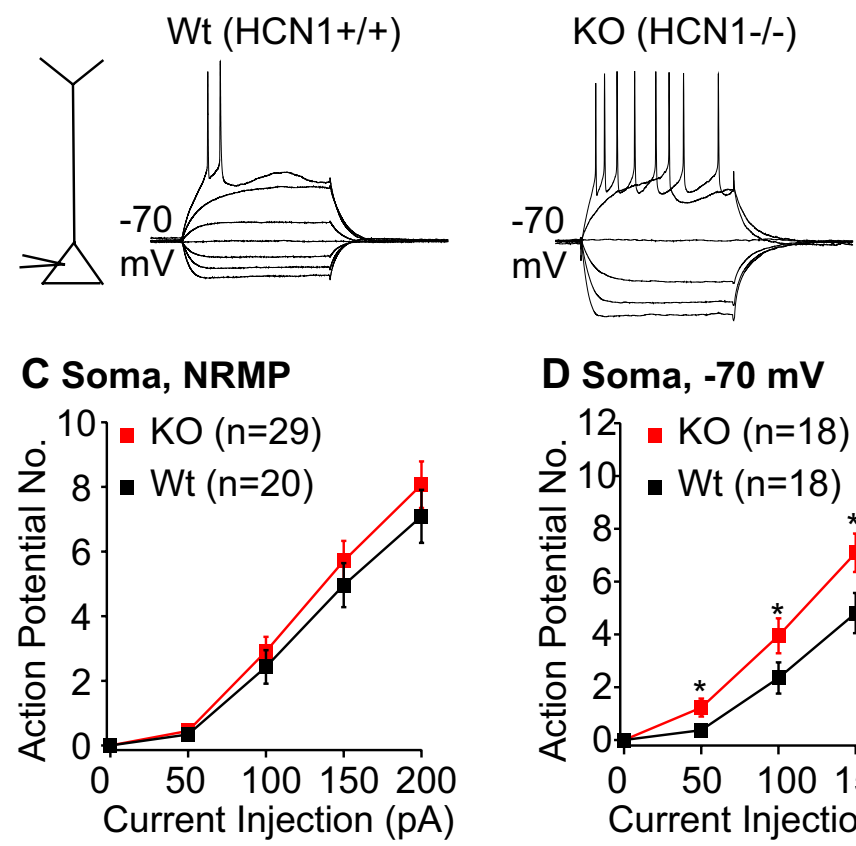

dendrites. Because Western blot analysis has shown that HCN2 levels are unaltered in these mice (Nolan et al., 2003), these results indicate that $\mathrm{HCN} 1$ subunits are essential for the generation of $I_{\mathrm{h}}$ in these neurons.

\section{Spontaneous activity and pyramidal cell dendritic excitability enhanced in $H C N 1-/-$ neurons}

To test how HCN1 deletion affected EC layer III pyramidal cell intrinsic membrane properties and excitability, we made whole-cell current-clamp recordings from the soma and dendrites of these neurons. In the absence of both GABA and glutamate receptor blockers, $\mathrm{HCN1}^{-/-}$neurons had significantly more hyperpolarized RMPs as well as more spontaneous activity than wild types (supplemental Fig. 1, available at www.jneurosci.org as supplemental material). The greater spontaneous postsynaptic potential frequency was detected in $\mathrm{HCN1}^{-/-}$neurons, even when the somatic RMP was artificially adjusted to $-70 \mathrm{mV}$ (supplemental Fig. 1, available at www.jneurosci.org as supplemental material), suggesting that EC neural network excitability was enhanced considerably more in $\mathrm{HCN1}^{-1-}$ mice compared with that of wild types. This may, at least partly, explain why the $\mathrm{HCN1}^{-/-}$mice were more susceptible to kainic acid-induced seizures.

The enhanced spontaneous postsynaptic potential frequency could be attributable to greater action potential-driven synaptic release resulting from altered intrinsic excitability of neurons. To assess this, spontaneous postsynaptic potential activity was first suppressed with glutamate and GABA receptor blockers (see Materials and Methods). Under these

Effects of HCN1 deletion on somatic intrinsic excitability. $\boldsymbol{A}, \boldsymbol{B}$, Example traces obtained from WT or HCN1 neurons in response to a series of $400 \mathrm{~ms}$ current steps from -150 to $+100 \mathrm{pA}$ in increments of $50 \mathrm{pA}$. The recordings have been obtained either at the normal resting membrane potential (NRMP) or at the fixed potential of $-70 \mathrm{mV}$. Calibration in $\boldsymbol{A}$ applies to all traces in $\boldsymbol{A}$ and $\boldsymbol{B}$. C, $\boldsymbol{D}$, Graphs to demonstrate average numbers of action potentials obtained in response to varying depolarizing current pulses when the soma was held at the NRMP or at $-70 \mathrm{mV} .{ }^{*} p<0.05$.

III neurons in particular (Du et al., 1993, 1995; Barbarosie and Avoli, 1997; Wu and Leung, 2003; Shah et al., 2004; Wozny et al., 2005; Ang et al., 2006) play a significant role during TLE, it is essential to determine how HCN1 ablation affects EC layer III cellular excitability. However, given that $\mathrm{HCN} 2$ subunits are also expressed in the EC, albeit to a much lower level than HCN1 subunits (Notomi and Shigemoto, 2004), it was first important to determine the extent to which $I_{\mathrm{h}}$ is reduced in $\mathrm{HCN1}^{-/-}$neurons. To investigate this, we made cell-attached voltage-clamp recordings from the soma and apical dendrite, $\sim 150 \mu \mathrm{m}$ from the soma [total EC layer III pyramidal neuron apical dendrite length, $\sim 250$ $\mu \mathrm{m}$ (Tahvildari and Alonso, 2005)]. $I_{\mathrm{h}}$ was activated by applying 3 s hyperpolarizing pulses from -40 to $-140 \mathrm{mV}$ in the presence of $\mathrm{Na}^{+}, \mathrm{K}^{+}$, and $\mathrm{Ca}^{2+}$ channel blockers (see Materials and Methods). In agreement with the reported predominant dendritic expression of HCN channels (Notomi and Shigemoto, 2004; Shah et al., 2004), a slowly activating current with an average steadystate magnitude of $19.25 \pm 3.3 \mathrm{pA}(n=8)$ (Fig. $2 A)$ was observed only in wild-type dendrites. The same protocol elicited no significant current $(0.86 \pm 1.43 \mathrm{pA} ; n=6)($ Fig. $2 \mathrm{~A})$ from $\mathrm{HCN}^{-/-}$ conditions, significantly larger numbers of action potentials could be recorded in $\mathrm{HCN1}^{-/-}$dendrites compared with wildtype neurons when depolarizing current pulses were applied despite a more hyperpolarized RMP $\left(\mathrm{HCN1}^{-/-}\right.$dendritic RMP, $-74.1 \pm 0.8 \mathrm{mV}, n=17$; wild-type dendritic RMP, $-68.9 \pm 0.9$ $\mathrm{mV}, n=10 ; p<0.05$ ) (Fig. $2 B$ ). A comparable effect could be produced by in wild-type dendrites if $I_{\mathrm{h}}$ was suppressed using the inhibitor ZD7288 [15 $\mu \mathrm{M}$, a maximal concentration (BoSmith et al., 1993)] (Fig. $3 A, C$ ). This inhibitor, however, did not affect $\mathrm{HCN1}^{-/-}$dendrite excitability (Fig. 3).

In accordance with the predominant dendritic location of HCN channels (see above), the differences in somatic action potentials elicited in response to depolarizing current steps were much smaller between $\mathrm{HCN1}^{-/-}$and wild-type neurons at their normal RMPs $\left(\mathrm{HCN1}^{-/-}\right.$somatic RMP, $-75.3 \pm 0.6 \mathrm{mV}, n=$ 33; wild-type somatic RMP, $-69.3 \pm 0.4 \mathrm{mV}, n=22 ; p<0.5$ ) (Fig. 4). If, however, all cells were artificially held at fixed potentials of $-70 \mathrm{mV}$, depolarizing current steps in $\mathrm{HCN1}^{-/-}$neurons produced significantly more action potentials (Fig. $4 A, B, E$ ). Application of $15 \mu \mathrm{M}$ ZD7288 affected wild-type somatic excitability 
in a similar manner (supplemental Fig. 2, available at www.jneurosci.org as supplemental material) but had no effect on $\mathrm{HCN}^{-/-}$somatic excitability (supplemental Fig. 2, available at www.jneurosci. org as supplemental material). There were also no differences in somatic or dendritic action potential shapes and threshold (measured at the soma; see Materials and Methods) between wildtype and $\mathrm{HCN1}^{-/-}$neurons (data not shown).

Why might more action potentials be recorded in dendrites, despite the hyperpolarized RMP? One possible reason might be altered dendritic input resistance $\left(R_{\mathrm{N}}\right)$ (Magee, 1998; Poolos et al., 2002; Shah et al., 2004; Tsay et al., 2007). Indeed, we noticed that hyperpolarizing and depolarizing current steps elicited bigger voltage deflections in $\mathrm{HCN1}^{-/-}$ dendrites compared with wild types, indicating that the $R_{\mathrm{N}}$ had changed (Fig. $2 B$ ). We, thus, measured $R_{\mathrm{N}}$ by applying $400 \mathrm{~ms}, 100 \mathrm{pA}$ hyperpolarizing current pulses from a holding potential of -70 $\mathrm{mV}$ (see Materials and Methods). Under these conditions, $R_{\mathrm{N}}$ was $\sim 200 \%$ greater in $\mathrm{HCN1}^{-/-}$dendrites than in wild types (dendritic $\mathrm{HCN1}^{-/-} R_{\mathrm{N}}, 188.52 \pm 16.04$ $\mathrm{M} \Omega, n=16$; dendritic wild-type $R_{\mathrm{N}}$, $62.47 \pm 8.48 \mathrm{M} \Omega, n=10 ; p<0.05$ ) (Fig. $5 A, C)$. Interestingly, although application of $15 \mu \mathrm{M}$ ZD7288 had little effect on $\mathrm{HCN}^{-/-}$dendrites (Fig. $5 A, D$ ), wildtype dendritic $R_{\mathrm{N}}$ was increased by $\sim 200 \%$ in the presence of the compound (Fig. $5 A, D$ ). In contrast, somatic $R_{\mathrm{N}}$ was only enhanced by $\sim 60 \%$ in $\mathrm{HCN1}^{-/-}$ neurons compared with wild types (somatic $\mathrm{HCN1}^{-/-} R_{\mathrm{N}}, 199.10 \pm 16.44 \mathrm{M} \Omega$, $n=21$; wild-type somatic $R_{\mathrm{N}}, 124.79 \pm$ 13.47 M $\Omega, n=19 ; p<0.05$ ) (Fig. $5 B, C$ ). Furthermore, $15 \mu \mathrm{M}$ ZD7228 also only augmented wild-type somatic $R_{\mathrm{N}}$ by $\sim 100 \%$ but had little effect on $\mathrm{HCN}^{-1-}$ neurons (Fig. $5 B, D$ ). These results confirm that $I_{\mathrm{h}}$ in EC layer III neurons is predominantly determined by $\mathrm{HCN} 1$ subunits. Furthermore, the findings demonstrate that, after HCN1 deletion or HCN pharmacological block, EC layer III pyramidal dendrites have enhanced excitability, at least partly attributable to substantially increased $R_{\mathrm{N}}$.

Greater dendritic synaptic integration and thereby neuronal firing in $\mathrm{HCN1}^{-1-}$ neurons

Alterations in $R_{\mathrm{N}}$ affect the amplitude and shapes of synaptic inputs and thereby their integration (Magee, 2000). Previous studies have shown that pharmacological block of dendritic HCN channels in hippocampal and cortical pyramids critically regulate temporal EPSP integration (Magee, 1999; Williams and Stuart, 2000; Berger et al., 2001; Poolos et al., 2002; Nolan et al., 2004, 2007; Shah et al., 2004; Kole et al., 2007). In agreement, we found that the amplitude and decay time constant $(\tau)$ of single $\alpha$ EPSPs
A Dendritic $\mathrm{R}_{\mathrm{N}}$
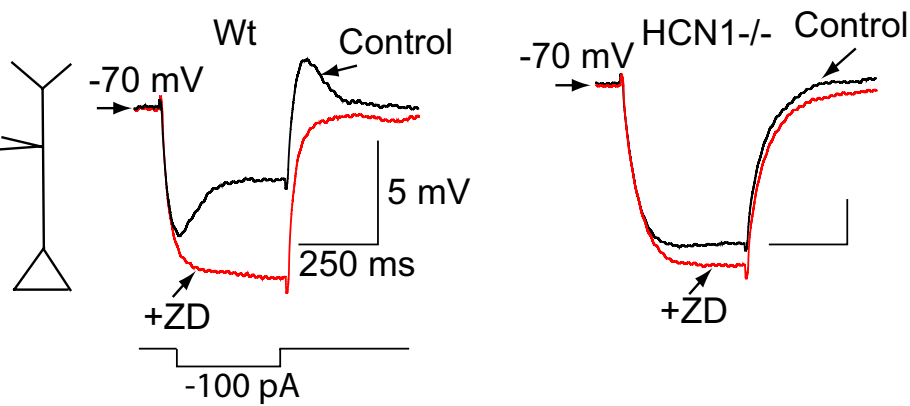

$-100 \mathrm{pA}$

B Somatic $\mathrm{R}_{\mathrm{N}}$
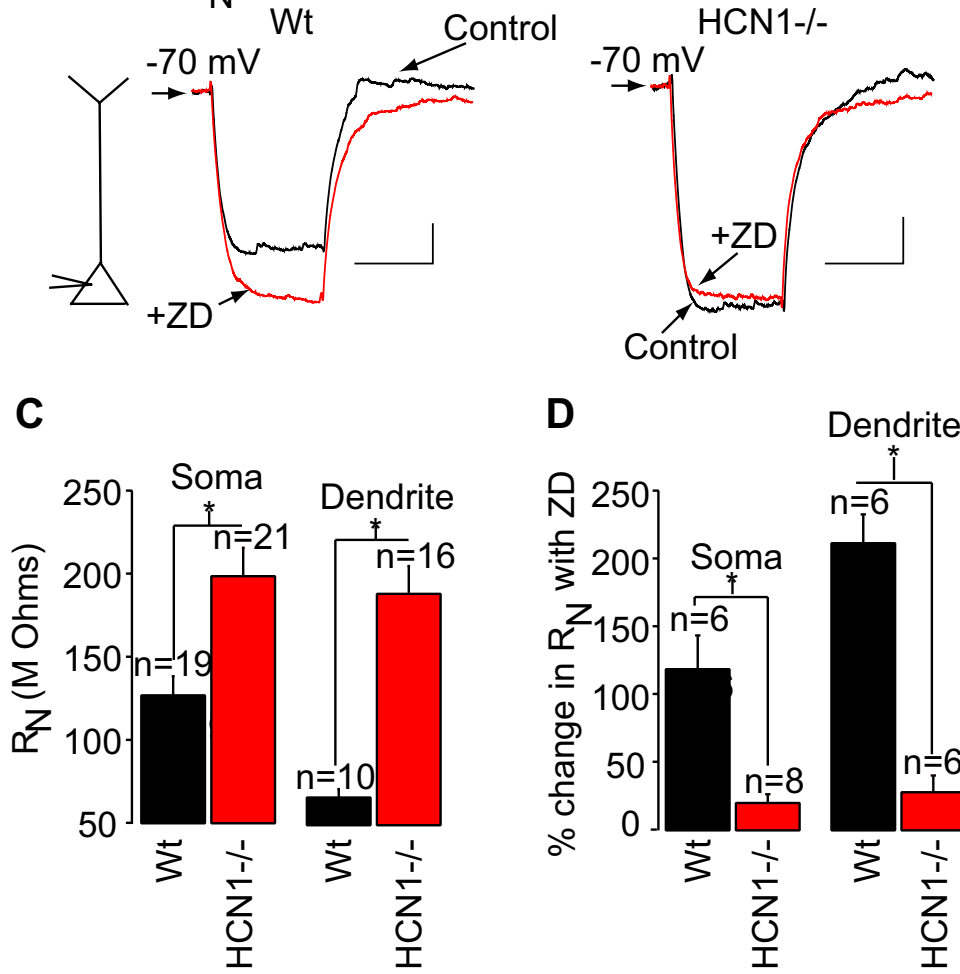

Figure 5. Enhanced $R_{\mathrm{N}}$ in $H C N 1^{-1-}$ neurons and after pharmacological block of $I_{\mathrm{h}}$ in wild-type neurons. $\boldsymbol{A}, \boldsymbol{B}$, Recordings obtained from $\sim 150 \mu$ m along the apical dendrite or the soma of WT (control) and $H C N 1^{-1}-$ EC layer Ill pyramidal neurons in the absence (black) and presence (red) of the $I_{\mathrm{h}}$ blocker, ZD7288 $(15 \mu \mathrm{m})$. All traces were obtained by applying a 100 pA hyperpolar$H C N 1^{-1-}$ neurons. D, Average percentage change in $R_{\mathrm{N}}$ after application of $15 \mu \mathrm{M}$ ZD7288 at the soma or dendrite of WT and $H C N 1^{-1-}$ neurons. Significance $(p<0.05)$ is illustrated using an asterisk.

was greater in $\mathrm{HCN1}^{-/-}$dendrites compared with wild types [dendritic $\alpha$ EPSP amplitude in $\mathrm{HCN1}^{-/-}$and wild type, $5.58 \pm$ $2.06 \mathrm{mV}(n=10)$ and $3.65 \pm 1.13 \mathrm{mV}(n=10), p<0.05$, respectively] (Figure $6 \mathrm{~A}$ ). Consequentially, the summation of a $50 \mathrm{~Hz}$ train of five $\alpha$ EPSPs was enhanced considerably more in $\mathrm{HCN1}^{-1-}$ dendrites than in wild-type dendrites (Fig. 6B). Somatic $\alpha$ EPSP amplitudes, in contrast, were no different between $\mathrm{HCN}^{-1-}$ and wild types ( $\mathrm{HCN} 1^{-1-}$ and wild-type somatic $\alpha$ EPSP amplitude $[4.05 \pm 1.80(n=11)$ and $3.42 \pm 0.97(n=11$; $p=0.32$ ), respectively]. Somatic $\alpha$ EPSP $\tau$, however, was also significantly slower in $\mathrm{HCN1}^{-/-}$neurons than wild types (Fig. $6 A, B)$. The difference, though, was substantially less than that between $\mathrm{HCN1}^{-1-}$ and wild-type dendrites (Fig. 6A,B). As a result, somatic $\alpha$ EPSPs summated more in $\mathrm{HCN}^{-/-}$neurons than in wild types (Fig. $6 B$ ), but the effect was smaller than in dendrites (Fig. 6A). 


\section{A $\alpha$ EPSP decay}
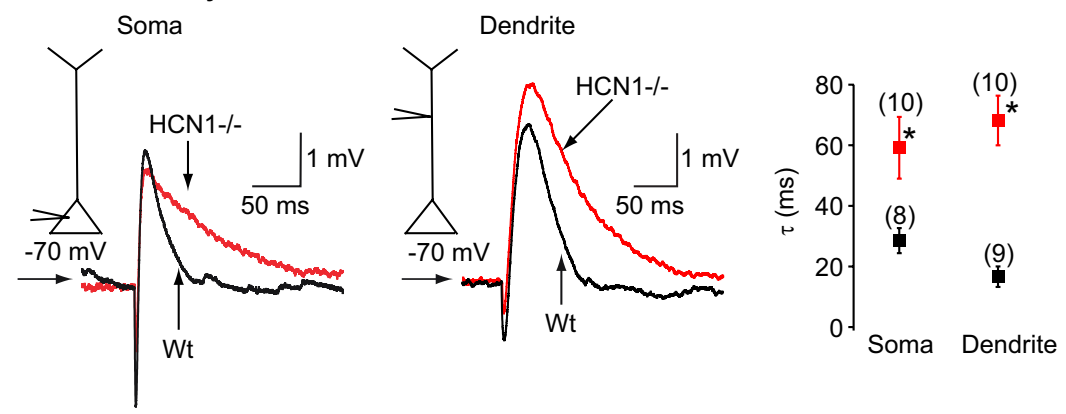

\section{B $\alpha$ EPSP summation} Soma
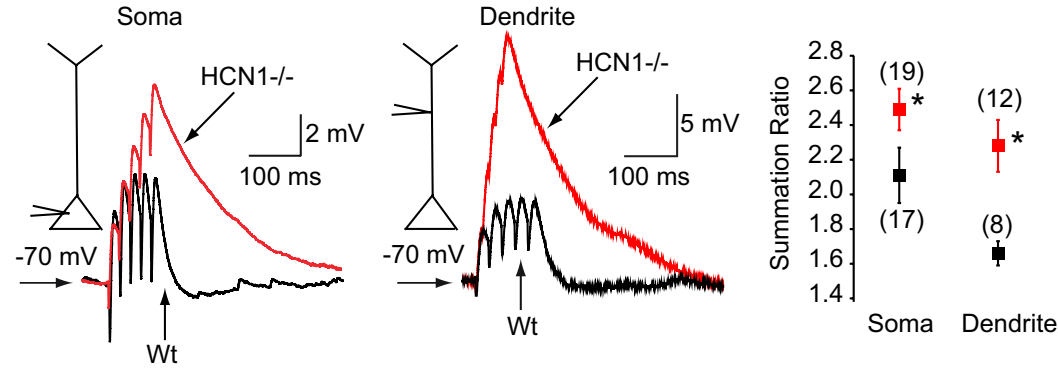

\section{Evoked EPSP summation}

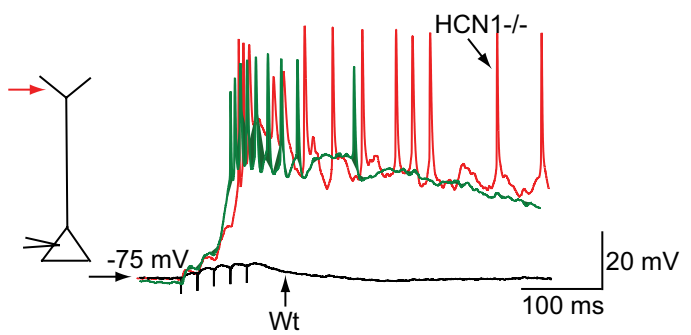

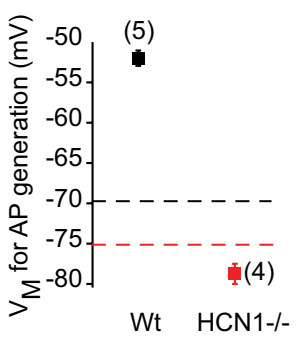

Wt HCN1-/-

Figure 6. Loss of HCN1 subunits leads to increased EPSP summation. Single $(\boldsymbol{A})$ and $50 \mathrm{~Hz}(\boldsymbol{B})$ trains of $\alpha$ EPSPs were generated by current injection (see Materials and Methods) at the soma or apical dendrite (100-150 $\mu \mathrm{m}$ from the soma) of $\mathrm{HCN1}^{-1-}$ (red trace) and WT (black trace) EC layer III neurons. All recordings were obtained at a fixed potential of $-70 \mathrm{mV}$. The average decay time constant ( $\tau$, obtained by fitting a two-exponential equation to the decay phase; see Materials and Methods) of single $\alpha$ EPSPs and the mean summation ratio (ratio of amplitude of 5th $\alpha$ EPSP to 1st $\alpha$ EPSP) of $50 \mathrm{~Hz}$ trains of $\alpha$ EPSPs obtained in WT (black points) and $\mathrm{HCN1}^{-1-}$ (red points) are shown on the panels on the right. The numbers of observations for each point are in brackets. Each trace is an average of five traces. The downward deflections at the beginning of each $\alpha$ EPSP are attributable to capacitance compensation. C, Example recordings obtained from the soma of $\mathrm{HCN1}^{-/-}$(red) and WT (black) neurons at a potential of $-75 \mathrm{mV}$ when five stimuli were applied extracellularly at a frequency of $50 \mathrm{~Hz}$ to the distal dendrites in the presence of $\mathrm{GABA}_{A}$ receptor inhibitors. Similar results were obtained in $\mathrm{HCN1}^{-/}$neurons in the absence of $\mathrm{GABA}_{\mathrm{A}}$ receptor inhibitors, too, as illustrated by the green trace. The stimulus strength was adjusted so that $1-2 \mathrm{mV}$ EPSP was generated by the first stimulus. The panel on the right shows the average somatic membrane potential of WT and $\mathrm{HCN1}^{-/-}$neurons at which a train of five EPSPs generated by extracellular stimulation produced an action potential. The black and red dotted lines indicate the average normal resting membrane potential for WT and $\mathrm{HCN1}^{-/-}$neurons, respectively. The numbers of recordings obtained for each point are shown in parentheses. Asterisks signify $p<0.05$.

To test whether the propensity for action potentials to be generated by a train of EPSPs is greater in $\mathrm{HCN1}^{-1-}$ neurons compared with wild types, we obtained whole-cell current-clamp recordings from the soma in the absence of glutamate blockers and minimally stimulated the afferent fibers to their distal dendrites (see Materials and Methods). The lack of glutamate inhibitors in the external medium resulted in a substantial increase in non-evoked EPSP frequency in $\mathrm{HCN1}^{-/-}$neurons (Fig. 7). In addition, considerably lower-amplitude extracellular stimulation of distal afferents was required to generate single 1-2 mV EPSPs in $\mathrm{HCN1}^{-1-}$ neurons than wild-type neurons. Despite the lower stimulation strength, however, a train of five stimuli delivered to distal $\mathrm{HCN1}^{-1-}$ dendrites generated epileptiform-like activity at normal RMP in these cells (Fig. 6C). In contrast, in wild types, a train of five evoked EPSPs did not summate sufficiently to produce an action potential unless the cell was depolarized above $-50 \mathrm{mV}$ (Fig. 6C). Interestingly, stimulation of distal $\mathrm{HCN1}^{-/-}$dendrites in the absence of $\mathrm{GABA}_{\mathrm{A}}$ receptor inhibitors also resulted in trains of action potentials at the normal RMP $(n=3)$ (Fig. $6 C)$. These results confirm that, like in hippocampal neurons (Nolan et al., 2004; Tsay et al., 2007), HCN1 subunits are fundamental for regulating the temporal summation of EPSPs in EC layer III pyramidal neurons and thus the tendency for action potentials to occur.

\section{Altered balance of spontaneous excitatory and inhibitory synaptic activity in $\mathrm{HCN1}^{-/-}$slices}

The above results suggest that, as a result of the enhanced activity of pyramidal cells, action potential-driven excitatory synaptic activity may be altered in $\mathrm{HCNI}^{-1-}$ tissue. To test whether this was the case, we recorded spontaneous, non-evoked EPSPs from $\mathrm{HCN1}^{-/-}$and wild-type EC layer III pyramidal neurons at a fixed potential of $-70 \mathrm{mV}$ using the whole-cell voltageclamp technique as described previously (Cossart et al., 2001; El-Hassar et al., 2007b). To eliminate effects of postsynaptic HCN channels and to reduce errors attributable to space clamp (Williams and Mitchell, 2008), $15 \mu \mathrm{M}$ ZD7288 was incorporated in the patch pipette. Although the presence of intracellular ZD7288 affected synaptic potential decay in wildtype neurons, it had no effect on their frequency (data not shown). In addition, inclusion of ZD7288 in the patch pipette resulted in the outward holding current of wild-type neurons increasing by $20.45 \pm$ $4.34 \mathrm{mV}(n=10)$, presumably as the RMP of the neurons became more hyperpolarized. In contrast, the outward holding current of $\mathrm{HCN1}^{-/-}$neurons was unaffected by the presence of ZD7288 $(n=9)$. To exclude inhibitory events, these experiments were done in the presence of GABA receptor blockers, bicuculline and CGP 55845. Under these conditions, the $\mathrm{HCN1}^{-/-}$EPSC frequency recorded was enhanced by approximately fourfold compared with wild types (wild-type EPSC frequency, $2.95 \pm 0.28, n=11 ; \mathrm{HCN1}^{-/-}$EPSC frequency, $11.08 \pm$ $1.36, n=10 ; p<0.05)($ Fig. $7 A)$. There were no differences in the amplitude or the kinetics of EPSCs (data not shown).

Because some EC inhibitory neurons may possibly have $I_{\mathrm{h}}$ (Kumar and Buckmaster, 2006), we also investigated whether action potential-driven IPSC frequency was altered by HCN1 deletion (see Materials and Methods). These experiments were performed in the absence of GABA receptor blockers but in the 


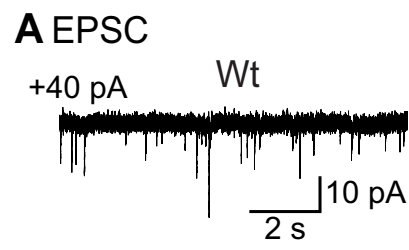

B IPSC

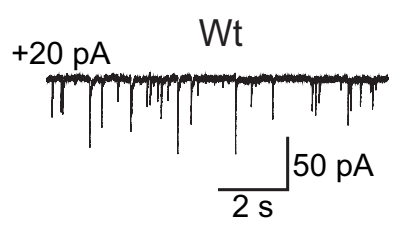

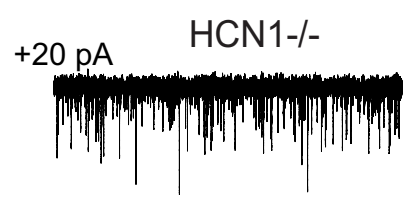

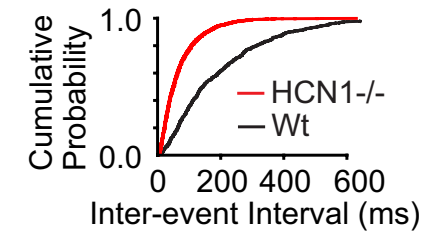

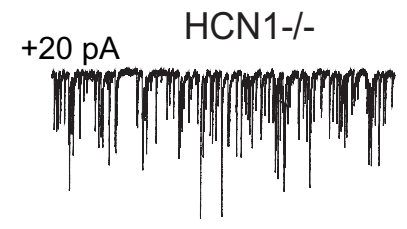

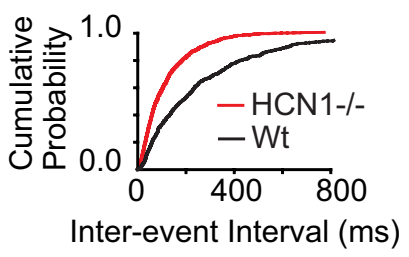

Figure 7. Differences in excitatory and inhibitory synaptic activity between $H C N 1^{-/-}$and wild-type slices. $A$, Example traces of EPSCs obtained under voltage-clamp conditions from WT and $\mathrm{HCN1}^{-1-}$ soma at a holding potential of $-70 \mathrm{mV}$ in the presence of the GABA receptor blockers bicuculline and CGP 55845 . The cumulative probability curves for the individual traces are shown, too. $B$, Example somatic IPSC recorded from WT and $\mathrm{HCN1}^{-1-}$ neurons under voltage-clamp conditions in the presence of the glutamate receptor blockers CNQX and APV. The intracellular solution in this case contained $140 \mathrm{~mm} \mathrm{KCl}$ (see Materials and Methods), and, thus, recordings were obtained at $-70 \mathrm{mV}$. The cumulative probability curves for each recording are also shown. For all EPSC and IPSC recordings, $15 \mu \mathrm{m} Z \mathrm{ZD} 7288$ was incorporated in the patch pipette to suppress postsynaptic HCN currents. Thus, the holding currents at $-70 \mathrm{mV}$ were often above $0 \mathrm{pA}$ (on average $+20 \mathrm{pA}$ ).

presence of glutamate receptor inhibitors. Although the IPSC amplitudes and kinetics were unaffected, the IPSC frequency was approximately twofold greater in $\mathrm{HCN1}^{-/-}$neurons (IPSC frequency, $7.50 \pm 2.35, n=9$ ) (Fig. $7 B$ ) compared with wild types (IPSC frequency, $4.65 \pm 0.59, n=9 ; p<0.05$ ) (Fig. $7 B$ ). Intriguingly, despite this, the EPSC frequency $(11.08 \pm 1.36, n=10)$ was still significantly more enhanced than the IPSC frequency in $\mathrm{HCN1}^{-/-}$neurons (Fig. 7). In contrast, in wild types, IPSCs occurred substantially more frequently than EPSCs (wild-type EPSC frequency, $2.95 \pm 0.28, n=11$ ) (Fig. 7). Hence, HCN1 deletion results in disproportionate rise in excitatory synaptic activity. Because this is a common feature during epilepsy, too (Scimemi et al., 2006; El-Hassar et al., 2007a), this might partly explain why $\mathrm{HCN1}^{-/-}$mice are more susceptible to seizure induction (Fig. 1).

\section{Discussion}

Multiple studies have shown previously that altered expression of HCN subunits is associated with TLE (Brewster et al., 2002; Bender et al., 2003; Shah et al., 2004; Jung et al., 2007; Powell et al., 2008; Shin et al., 2008; Marcelin et al., 2009). In this study, we now demonstrate that a lack of HCN1 subunits is likely to significantly influence seizure threshold as well as the process of TLE. Although in vivo EEG recordings showed that $\mathrm{HCN1}^{-/-}$mice were not inherently epileptic, these mice were significantly more vulnerable to kainic acid-induced seizures (Fig. 1). Furthermore, after termination of kainic acid-induced seizures, HCN1 null mice developed overt behavioral seizures (chronic epilepsy) at an approximately six times faster rate than wild-type littermate controls (Fig. 1). In vitro electrophysiological experiments showed that the greater seizure susceptibility of $\mathrm{HCN} 1$ null mice could, at least partly, be attributed to the enhanced excitability of EC layer III neurons, caused by lack of dendritic $I_{\mathrm{h}}$ (Fig. 2). This is likely to have contributed to increased excitatory synaptic transmission (Fig. 7), and consequentially there was an imbalance in excitatory and inhibitory synaptic activity (Fig. 7). Hence, HCN channels by regulating dendritic intrinsic membrane properties and, thereby, pyramidal cell excitability are able to influence cortical neural network activity.

\section{Significance of dendritic HCN1 channels for pyramidal cell excitability}

The lack of HCN1 subunits resulted in the ablation of $I_{\mathrm{h}}$ in EC layer III pyramidal neurons (Fig. 2), which are known to play a significant part in the progress of TLE (Du et al., 1993, 1995; Jones, 1993; Barbarosie and Avoli, 1997; Avoli et al., 2002; Wu and Leung, 2003; Shah et al., 2004; Wozny et al., 2005; Ang et al., 2006). Consistent with this, the RMP was considerably more hyperpolarized and $R_{\mathrm{N}}$ significantly greater in $\mathrm{HCN1}^{-/-}$neurons compared with wild-type littermate controls (Figs. 2, 4). The greater $R_{\mathrm{N}}$ would give rise to bigger voltage deflections in response to depolarizing pulses (Figs. 2, 4). This in conjunction with increased $\mathrm{Na}^{+}$and $\mathrm{Ca}^{2+}$ channel availability attributable to the hyperpolarized RMP (Tsay et al., 2007) is likely to explain why more action potentials were elicited in $\mathrm{HCN1}^{-/-}$dendrites than wild-type dendrites in response to the depolarizing current pulses of similar magnitude (Fig. 2). This effect was not noticeable at the soma because, in agreement with the predominant dendritic location of HCN1 subunits (Figs. 2, 3) (Notomi and Shigemoto, 2004; Shah et al., 2004), somatic $R_{\mathrm{N}}$ was less affected by the loss of HCN1 subunits (Fig. 5). In addition, because of the significantly enhanced dendritic $R_{\mathrm{N}}$ (Fig. 5), EPSP integration in $\mathrm{HCN1}^{-/-}$ dendrites was considerably greater than in wild-type dendrites (Fig. 6). Consequentially, trains of excitatory synaptic inputs that did not elicit action potentials in wild-type neurons unless they were substantially depolarized resulted in epileptiform-like activity in $\mathrm{HCN1}^{-/-}$neurons at their normal RMP (Fig. 6). Thus, these results, in accordance with those obtained in previous studies (Shah et al., 2004; Tsay et al., 2007), indicate that dendritic $I_{\mathrm{h}}$ acts an electrical shunt, normalizing any significant changes in voltage. In this manner, dendritic $I_{\mathrm{h}}$ in these neurons also contributes to regulating action potential-driven output.

\section{Consequences of HCN1 loss on neural network activity}

Under physiological conditions, experimental evidence suggests that excitatory and inhibitory inputs onto cortical neurons are proportional and balanced, allowing stability of neural network activity (Shu et al., 2003; Haider et al., 2006). Application of ZD7288 has been shown previously to boost action potential fir- 
ing and thereby recurrent network activity in prefrontal cortex (Wang et al., 2007). In agreement, our findings also suggest that a loss of HCN1, by increasing the propensity for action potentials to occur in pyramidal cells with any given synaptic input (Fig. $6 C$ ), would lead to greater neuronal output and hence substantially more synaptic activity. Indeed, action potential-driven $\mathrm{HCN1}^{-/-}$EPSC frequency was enhanced fourfold (Fig. 7A). However, this might also be predicted to augment interneuron activity and thereby raise inhibition (Dugladze et al., 2007). Furthermore, some interneurons have been suggested to have $I_{\mathrm{h}}$ (McBain and Fisahn, 2001; Aponte et al., 2006; Kumar and Buckmaster, 2006; Dugladze et al., 2007), and a loss of $I_{\mathrm{h}}$ may contribute to greater activity of these (Dugladze et al., 2007). Although we did not test whether interneuron activity per se was altered as a consequence of either enhanced synaptic activation or a loss of $I_{\mathrm{h}}$, our findings suggested that this might be the case because IPSC frequency onto EC layer III pyramidal neurons was amplified (Fig. 7B). Despite this, the EPSC/IPSC ratio changed from 0.63 in wild types to 1.47 in $\mathrm{HCN1}^{-1-}$ neurons (Fig. 7). Hence, loss of HCN1 subunits leads to a disproportionate increase in excitatory synaptic activity.

\section{Implications of HCN1 plasticity for epilepsy}

We have shown that a lack of HCN1 subunits results in EC layer III pyramidal cell hyperexcitability, enhanced action potentialdriven spontaneous $\mathrm{HCN1}^{-/-}$EPSC frequency and, thus, altered EC neural network activity. Previous studies have also demonstrated that HCN1 deletion results in greater dendritic excitability and EPSP summation in hippocampal pyramidal CA1 neurons (Nolan et al., 2004; Tsay et al., 2007), which are involved in seizure generation during TLE too (Spencer and Spencer, 1994). It is thus surprising that interictal spikes or electrographic seizures were not observed in $\mathrm{HCN1}^{-/-}$mice in vivo (Fig. 1) (Nolan et al., 2004). However, the amplified IPSC frequency, although this was to a much lower extent than excitatory synaptic transmission (Fig. 7), together with increased IPSC summation caused by loss of $I_{\mathrm{h}}$ (Chen et al., 2001) might serve to offset the heightened neural network activity and thereby prevent the occurrence of inherent interictal spikes or seizures. Hence, although the reduction of HCN1 subunit clearly favors neural network excitability (supplemental Fig. 1, available at www.jneurosci.org as supplemental material) (Fig. 7), the imbalance between excitation and inhibition may be insufficient to render $\mathrm{HCN1}^{-/-}$ mice spontaneously epileptic.

The $\mathrm{HCN1}^{-/-}$mice, though, were clearly more susceptible to seizures and developed chronic TLE at a much faster rate than wild-type littermates (Fig. 1). Multiple studies have demonstrated that HCN1 subunit expression is reduced after status epilepticus (Brewster et al., 2002; Shah et al., 2004; Dugladze et al., 2007; Jung et al., 2007; Powell et al., 2008; Shin et al., 2008; Marcelin et al., 2009). Hence, the latent period duration might be expected to be comparable between wild types and $\mathrm{HCN} 1^{-/-}$ mice after TLE induction. However, it should be noted that $\mathrm{HCN} 1$ expression in wild types is not ablated in the hippocampus or cortex after TLE (Brewster et al., 2002; Shah et al., 2004; Dugladze et al., 2007; Jung et al., 2007; Powell et al., 2008; Shin et al., 2008; Marcelin et al., 2009). Indeed, in hippocampal CA1 dendrites, depending on the time point of measurement and model used, the decrease in $I_{\mathrm{h}}$ after status epilepticus in wild types can vary between 30 and 50\% (Jung et al., 2007; Shin et al., 2008; Marcelin et al., 2009). Furthermore, somatic HCN1 subunit expression may also be transiently enhanced in CA1 pyramidal cells after TLE in wild types (Shin et al., 2008). Moreover, it is not known whether status epilepticus results in altered HCN1 protein levels in all wild-type neurons expressing HCN1 subunits. In contrast, in $\mathrm{HCN1}^{-/-}$mice, $I_{\mathrm{h}}$ is persistently reduced by $\sim 70 \%$ in CA1 neurons (Nolan et al., 2004). Thus, variations in HCN1 levels may explain the difference in latent period duration after termination of status epilepticus in wild-type and $\mathrm{HCN1}^{-/-}$ mice. Nonetheless, our results show that the decline in $\mathrm{HCN}$ subunit expression after TLE induction is likely to contribute to the condition.

\section{References}

Ang CW, Carlson GC, Coulter DA (2006) Massive and specific dysregulation of direct cortical input to the hippocampus in temporal lobe epilepsy. J Neurosci 26:11850-11856.

Aponte Y, Lien CC, Reisinger E, Jonas P (2006) Hyperpolarizationactivated cation channels in fast-spiking interneurons of rat hippocampus. J Physiol 574:229-243.

Avoli M, D’Antuono M, Louvel J, Köhling R, Biagini G, Pumain R, D'Arcangelo G, Tancredi V (2002) Network and pharmacological mechanisms leading to epileptiform synchronization in the limbic system in vitro. Prog Neurobiol 68:167-207.

Barbarosie M, Avoli M (1997) CA3-driven hippocampal-entorhinal loop controls rather than sustains in vitro limbic seizures. J Neurosci 17:9308-9314.

Barbarosie M, Louvel J, Kurcewicz I, Avoli M (2000) CA3-Released entorhinal seizures disclose dentate gyrus epileptogenicity and unmask a temporoammonic pathway. J Neurophysiol 83:1115-1124.

Ben-Ari Y, Cossart R (2000) Kainate, a double agent that generates seizures: two decades of progress. Trends Neurosci 23:580-587.

Bender RA, Soleymani SV, Brewster AL, Nguyen ST, Beck H, Mathern GW, Baram TZ (2003) Enhanced expression of a specific hyperpolarizationactivated cyclic nucleotide-gated cation channel $(\mathrm{HCN})$ in surviving dentate gyrus granule cells of human and experimental epileptic hippocampus. J Neurosci 23:6826-6836.

Berger T, Larkum ME, Lüscher HR (2001) High I(h) channel density in the distal apical dendrite of layer $\mathrm{V}$ pyramidal cells increases bidirectional attenuation of EPSPs. J Neurophysiol 85:855-868.

BoSmith RE, Briggs I, Sturgess NC (1993) Inhibitory actions of ZENECA ZD7288 on whole-cell hyperpolarization activated inward current (If) in guinea-pig dissociated sinoatrial node cells. Br J Pharmacol 110:343-349.

Brewster A, Bender RA, Chen Y, Dube C, Eghbal-Ahmadi M, Baram TZ (2002) Developmental febrile seizures modulate hippocampal gene expression of hyperpolarization-activated channels in an isoform- and cellspecific manner. J Neurosci 22:4591-4599.

Chen K, Aradi I, Thon N, Eghbal-Ahmadi M, Baram TZ, Soltesz I (2001) Persistently modified h-channels after complex febrile seizures convert the seizure-induced enhancement of inhibition to hyperexcitability. Nat Med 7:331-337.

Cossart R, Dinocourt C, Hirsch JC, Merchan-Perez A, De Felipe J, Ben-Ari Y, Esclapez M, Bernard C (2001) Dendritic but not somatic GABAergic inhibition is decreased in experimental epilepsy. Nat Neurosci 4:52-62.

Dawodu S, Thom M (2005) Quantitative neuropathology of the entorhinal cortex region in patients with hippocampal sclerosis and temporal lobe epilepsy. Epilepsia 46:23-30.

Du F, Whetsell WO Jr, Abou-Khalil B, Blumenkopf B, Lothman EW, Schwarcz R (1993) Preferential neuronal loss in layer III of the entorhinal cortex in patients with temporal lobe epilepsy. Epilepsy Res 16:223-233.

Du F, Eid T, Lothman EW, Köhler C, Schwarcz R (1995) Preferential neuronal loss in layer III of the medial entorhinal cortex in rat models of temporal lobe epilepsy. J Neurosci 15:6301-6313.

Dudek FE, Hellier JL, Williams PA, Ferraro DJ, Staley KJ (2002) The course of cellular alterations associated with the development of spontaneous seizures after status epilepticus. Prog Brain Res 135:53-65.

Dugladze T, Vida I, Tort AB, Gross A, Otahal J, Heinemann U, Kopell NJ, Gloveli T (2007) Impaired hippocampal rhythmogenesis in a mouse model of mesial temporal lobe epilepsy. Proc Natl Acad Sci U S A 104:17530-17535.

Dyhrfjeld-Johnsen J, Morgan RJ, Földy C, Soltesz I (2008) Upregulated $\mathrm{H}$-current in hyperexcitable CA1 dendrites after febrile seizures. Front Cell Neurosci 2:2. 
El-Hassar L, Esclapez M, Bernard C (2007a) Hyperexcitability of the CA1 hippocampal region during epileptogenesis. Epilepsia 48 [Suppl 5]:131-139.

El-Hassar L, Milh M, Wendling F, Ferrand N, Esclapez M, Bernard C (2007b) Cell domain-dependent changes in the glutamatergic and GABAergic drives during epileptogenesis in the rat CAl region. J Physiol 578:193-211.

Engel J Jr (1996) Introduction to temporal lobe epilepsy. Epilepsy Res 26:141-150.

Haider B, Duque A, Hasenstaub AR, McCormick DA (2006) Neocortical network activity in vivo is generated through a dynamic balance of excitation and inhibition. J Neurosci 26:4535-4545.

He XP, Kotloski R, Nef S, Luikart BW, Parada LF, McNamara JO (2004) Conditional deletion of TrkB but not BDNF prevents epileptogenesis in the kindling model. Neuron 43:31-42.

Herman ST (2002) Epilepsy after brain insult: targeting epileptogenesis. Neurology 59:S21-S26.

Jones RS (1993) Entorhinal-hippocampal connections: a speculative view of their function. Trends Neurosci 16:58-64.

Jung S, Jones TD, Lugo JN Jr, Sheerin AH, Miller JW, D’Ambrosio R, Anderson AE, Poolos NP (2007) Progressive dendritic HCN channelopathy during epileptogenesis in the rat pilocarpine model of epilepsy. J Neurosci 27:13012-13021.

Kole MH, Bräuer AU, Stuart GJ (2007) Inherited cortical HCN1 channel loss amplifies dendritic calcium electrogenesis and burst firing in a rat absence epilepsy model. J Physiol 578:507-525.

Kumar SS, Buckmaster PS (2006) Hyperexcitability, interneurons, and loss of GABAergic synapses in entorhinal cortex in a model of temporal lobe epilepsy. J Neurosci 26:4613-4623.

Lehmkuhle MJ, Thomson KE, Scheerlinck P, Pouliot W, Greger B, Dudek FE (2009) A simple quantitative method for analyzing electrographic status epilepticus in rats. J Neurophysiol 101:1660-1670.

Lörincz A, Notomi T, Tamás G, Shigemoto R, Nusser Z (2002) Polarized and compartment-dependent distribution of HCN1 in pyramidal cell dendrites. Nat Neurosci 5:1185-1193.

Magee JC (1998) Dendritic hyperpolarization-activated currents modify the integrative properties of hippocampal CAl pyramidal neurons. J Neurosci 18:7613-7624.

Magee JC (1999) Dendritic lh normalizes temporal summation in hippocampal CA1 neurons. Nat Neurosci 2:508-514.

Magee JC (2000) Dendritic integration of excitatory synaptic input. Nat Rev Neurosci 1:181-190.

Marcelin B, Chauvière L, Becker A, Migliore M, Esclapez M, Bernard C (2009) h channel-dependent deficit of theta oscillation resonance and phase shift in temporal lobe epilepsy. Neurobiol Dis 33:436-447.

McBain CJ, Fisahn A (2001) Interneurons unbound. Nat Rev Neurosci 2:11-23.

Nolan MF, Malleret G, Lee KH, Gibbs E, Dudman JT, Santoro B, Yin D, Thompson RF, Siegelbaum SA, Kandel ER, Morozov A (2003) The hyperpolarization-activated $\mathrm{HCN} 1$ channel is important for motor learning and neuronal integration by cerebellar Purkinje cells. Cell 115:551-564.

Nolan MF, Malleret G, Dudman JT, Buhl DL, Santoro B, Gibbs E, Vronskaya S, Buzsáki G, Siegelbaum SA, Kandel ER, Morozov A (2004) A behavioral role for dendritic integration: HCN1 channels constrain spatial memory and plasticity at inputs to distal dendrites of CA1 pyramidal neurons. Cell 119:719-732.

Nolan MF, Dudman JT, Dodson PD, Santoro B (2007) HCN1 channels control resting and active integrative properties of stellate cells from layer II of the entorhinal cortex. J Neurosci 27:12440-12451.
Notomi T, Shigemoto R (2004) Immunohistochemical localization of Ih channel subunits, HCN1-4, in the rat brain. J Comp Neurol 471:241-276.

Pape HC (1996) Queer current and pacemaker: the hyperpolarizationactivated cation current in neurons. Annu Rev Physiol 58:299-327.

Poolos NP, Migliore M, Johnston D (2002) Pharmacological upregulation of h-channels reduces the excitability of pyramidal neuron dendrites. Nat Neurosci 5:767-774.

Powell KL, Ng C, O’Brien TJ, Xu SH, Williams DA, Foote SJ, Reid CA (2008) Decreases in HCN mRNA expression in the hippocampus after kindling and status epilepticus in adult rats. Epilepsia 49:1686-1695.

Racine RJ (1972) Modification of seizure activity by electrical stimulation. I. After-discharge threshold. Electroencephalogr Clin Neurophysiol 32:269-279.

Robinson RB, Siegelbaum SA (2003) Hyperpolarization-activated cation currents: from molecules to physiological function. Annu Rev Physiol 65:453-480.

Scimemi A, Schorge S, Kullmann DM, Walker MC (2006) Epileptogenesis is associated with enhanced glutamatergic transmission in the perforant path. J Neurophysiol 95:1213-1220.

Shah MM, Anderson AE, Leung V, Lin X, Johnston D (2004) Seizureinduced plasticity of $\mathrm{h}$ channels in entorhinal cortical layer III pyramidal neurons. Neuron 44:495-508.

Shin M, Brager D, Jaramillo TC, Johnston D, Chetkovich DM (2008) Mislocalization of $\mathrm{h}$ channel subunits underlies $\mathrm{h}$ channelopathy in temporal lobe epilepsy. Neurobiol Dis 32:26-36.

Shu Y, Hasenstaub A, McCormick DA (2003) Turning on and off recurrent balanced cortical activity. Nature 423:288-293.

Spencer SS, Spencer DD (1994) Entorhinal-hippocampal interactions in medial temporal lobe epilepsy. Epilepsia 35:721-727.

Stuart G, Spruston N (1998) Determinants of voltage attenuation in neocortical pyramidal neuron dendrites. J Neurosci 18:3501-3510.

Tahvildari B, Alonso A (2005) Morphological and electrophysiological properties of lateral entorhinal cortex layers II and III principal neurons. J Comp Neurol 491:123-140.

Truett GE, Heeger P, Mynatt RL, Truett AA, Walker JA, Warman ML (2000) Preparation of PCR-quality mouse genomic DNA with hot sodium hydroxide and tris (HotSHOT). Biotechniques 29:52:54.

Tsay D, Dudman JT, Siegelbaum SA (2007) HCN1 channels constrain synaptically evoked $\mathrm{Ca}^{2+}$ spikes in distal dendrites of CA1 pyramidal neurons. Neuron 56:1076-1089.

Wang M, Ramos BP, Paspalas CD, Shu Y, Simen A, Duque A, Vijayraghavan S, Brennan A, Dudley A, Nou E, Mazer JA, McCormick DA, Arnsten AF (2007) Alpha2A-adrenoceptors strengthen working memory networks by inhibiting cAMP-HCN channel signaling in prefrontal cortex. Cell 129:397-410.

White HS (2002) Animal models of epileptogenesis. Neurology 59:S7-S14. Williams PA, White AM, Clark S, Ferraro DJ, Swiercz W, Staley KJ, Dudek FE (2009) Development of spontaneous recurrent seizures after kainateinduced status epilepticus. J Neurosci 29:2103-2112.

Williams SR, Mitchell SJ (2008) Direct measurement of somatic voltage clamp errors in central neurons. Nat Neurosci 11:790-798.

Williams SR, Stuart GJ (2000) Site independence of EPSP time course is mediated by dendritic $\mathrm{I}(\mathrm{h})$ in neocortical pyramidal neurons. J Neurophysiol 83:3177-3182.

Wozny C, Gabriel S, Jandova K, Schulze K, Heinemann U, Behr J (2005) Entorhinal cortex entrains epileptiform activity in CA1 in pilocarpinetreated rats. Neurobiol Dis 19:451-460.

Wu K, Leung LS (2003) Increased dendritic excitability in hippocampal cal in vivo in the kainic acid model of temporal lobe epilepsy: a study using current source density analysis. Neuroscience 116:599-616. 